\title{
Advies 2/13 van het Hof van Justitie: flinke stap terug voor toetreding Europese Unie tot Europees Verdrag tot bescherming van de rechten van de mens
}

\author{
Dr. C.J. Van de Heyning*
}

In Advies 2/13 oordeelt het Hof van Justitie dat het Ontwerpakkoord aangaande de toetreding van de Europese Unie tot het EVRM niet in overeenstemming is met de Verdragen. Het Hof van Justitie meent dat het Ontwerpakkoord op elf punten in strijd is met de autonomie en eigenheid van het Unierecht (de eenheid, voorrang en effectiviteit van het Unierecht) en de positie van het Hof van Justitie als ultieme rechter over de interpretatie van het Unierecht in gevaar brengt. Dit Advies werd ontvangen als een grote verrassing. Deze annotatie bespreekt het Advies en besluit dat het Hof van Justitie hiermee de toetreding zeer moeilijk zo niet onmogelijk maakt.

Hvf 18 december 2014, Advies 2/13, Advies aangaande artikel 218, paragraaf 11 VWEU, ECLI:EU:C: 2014:2475, n.n.g.

\section{De lange aanloop naar de toetreding van de EU tot het EVRM}

De toetreding van de EU tot het EVRM kent een lange aanloop. Reeds in 1979 stelde de Europese Commissie de toetreding tot het EVRM voor om het gebrek aan een eigen mensenrechtenkader in het Europese economische project van de toenmalige Europese Gemeenschap te

compenseren. ${ }^{1}$ Zelfs al ontwikkelde het Hof van Justitie een uitgebreide fundamentelerechtenjurisprudentie en werd met de Verklaring van Nice een eigen mensenrechtendocument, het Handvest van de Grondrechten van de EU, geïntroduceerd, toch bleven er voldoende redenen voor de toetreding van de EU tot het EVRM: de zeer beperkte rechtstreekse toegang voor individuen tot de Europese rechtscolleges door de strenge ontvankelijkheidscriteria, ${ }^{2}$ het gebrek aan enige rechterlijke toetsing van het gemeenschappelijk buitenlands en veiligheidsbeleid, ${ }^{3}$ of de vrees voor verschillende interpretatie van analoge mensenrechten door het Hof van Justitie en het EHRM. ${ }^{4}$ Bovendien bepaalde het EHRM dat het nationale maatregelen of normen niet zal toetsen indien deze rechtstreeks volgen uit de verplichtingen onder het EU-lidmaatschap van de lidstaat op voorwaarde dat de lidstaat geen discretionaire ruimte had bij de omzetting en er geen manifeste schending is van het

1. Memorandum aangaande de toetreding van de Europese Gemeenschappen tot het Europees Verdrag voor de Bescherming van de Rechten van de Mens en Fundamentele Vrijheden COM (79)210 final, 2 mei 1979, Bulletin of the European Communities, Supplement 2/79.

2. Dit volgde in het bijzonder uit het arrest Plauman: HvJ 15 juli 1963, zaak C-25/62, Plaumann \& Co./Commissie, ECLI:EU:C:1963:17, Jur. 1963 , p. 199. Weliswaar versoepelde het Verdrag van Lissabon enigszins deze criteria, de rechtstreekse toegang blijft bijzonder beperkt. Zie hierover M. Eliantonio en B. Kas, 'Private parties and the annulment procedure: can the gap in the European system of judicial protection be closed?', Journal of Politics and Law 2010, nr. 2, p. 121-133 en R. Baratta, 'Accession of the EU to the ECHR: the rationale for the ECJ's prior involvement mechanism', Common market law review 2013, p. $1305-1332$.

3. Art. 24 lid $1 \mathrm{VEU}$.

4. De Parlementaire Vergadering van de Raad van Europa verklaarde in 2008 dat zonder toetreding de coherentie van de Europese bescherming van mensenrechten niet volledig verzekerd is. Parlementaire Vergadering, Rapport van het comité voor Juridische zaken en Mensenrechten aangaande de toetreding van de Europese Unie tot het Europees Verdrag voor de Rechten Van de Mens, Doc. 11533, 18 maart 2008 , punt 6 . 
EVRM. ${ }^{5}$ Omdat steeds meer nationale regels volgen uit de omzetting van het Unierecht, ontsnapt een groot deel van de nationale regels aan de controle van het EHRM. Om bovenstaande redenen bepaalde het Verdrag van Lissabon dan ook dat de Europese Unie zou toetreden tot het EVRM.

Pas in het Verdrag van Lissabon werd de bevoegdheid tot toetreding effectief ingeschreven in artikel 6 lid 2 VEU. Bovendien werd een protocol toegevoegd aan de Verdragen (protocol 8) dat de randvoorwaarden voor de toetreding vastlegt. De verdragsluitende partijen van de Raad van Europa keurden daarop het protocol goed dat de toetreding mogelijk maakt. ${ }^{6}$ In 2011 verscheen uiteindelijk een eerste voorstel van het Ontwerpakkoord en in 2013 een gefinaliseerde versie. ${ }^{7}$ Dit Ontwerpakkoord voorziet in verschillende amendementen op het EVRM die de gevolgen van de toetreding regelen. Een advies van het Hof van Justitie over de verenigbaarheid van het Ontwerpakkoord met de Verdragen was de volgende horde voor de toetreding. Algemeen werd aangenomen dat het Hof van Justitie de toetreding niet in de weg zou staan gezien de harmonieuze samenwerking tussen het Hof van Justitie en het Europees Hof voor de Rechten van de Mens ${ }^{8}$ en de grote zorg die besteed was aan het vorige advies $^{9}$ van het Hof van Justitie over een mogelijke toetreding bij het opstellen van het Ontwerpakkoord. Groot was dan ook de verbazing toen het Hof van Justitie in zijn Advies 2/13 het Ontwerpakkoord scherp aanviel en besloot: 'De overeenkomst inzake de toetreding van de Europese Unie tot het Europees Verdrag tot de bescherming van de rechten van de mens en de fundamentele vrijheden is niet verenigbaar met artikel 6 , lid 2 , VEU en evenmin met protocol (nr. 8).' (punt 258).

\section{Het Ontwerpakkoord}

Het Ontwerpakkoord ${ }^{10}$ voorziet in de toetreding van de EU tot het EVRM, het $1^{\text {ste }}$ Protocol EVRM en tot het

5. Dit is de zogenoemde Bosphorus-doctrine: EHRM 30 juni 2005, appl.nr. 45036/98, Bosphorus/lerland, EHRC 2005/91, m.nt. Bulterman. Zie hierover J. Callewaert, 'Het EVRM en de Europese Unie: van Bosphorus naar Lissabon', NTER 2010/3, p. 101-107.

6. Protocol nr. 14 EVRM voerde het nieuwe art. 59 lid 2 EVRM in, dat bepaalt: 'De Europese Unie kan toetreden tot dit Verdrag.'

7. Voorstel juridisch instrument aangaande de toetreding van de Europese Unie tot het EVRM, 19 juli 2011, CDDH-UE(2011)16.

8. Zie bijvoorbeeld de gezamenlijke communicatie van presidenten Skouris en Costa aangaande de toetreding. Verkrijgbaar op <www.echr.coe. int>.

9. HvJ 28 maart 1996, Advies 2/94, Advies over de toetreding van de Gemeenschap tot het Verdrag tot bescherming van de rechten van de mens en de fundamentele vrijheden, ECLI:EU:C:1996:140, Jur. 1996, p. I-1759.

10. Voor een uitgebreidere analyse van het Ontwerpakkoord zie F.D. Schild, 'Hoe een koe een haas vangt. De toetreding van de EU tot het EVRM en de gevolgen voor de praktijk', NTER 2013/7, p. 247-254. $6^{\text {de }}$ Protocol EVRM. ${ }^{11}$ Justitiabelen zullen na de inwerkingtreding van dit akkoord een klacht tegen de EU kunnen indienen voor de schending van het EVRM door handelingen door EU-instellingen of het Unierecht. $^{12}$ De EU zal gebonden zijn door het op zo'n klacht gewezen arrest van het EHRM. ${ }^{13}$ Afhankelijk van de analyse of een schending van het EVRM het rechtstreeks gevolg is van een EU-handeling of de lidstaat zal de klager zich moeten richten tegen de EU of de lidstaat. Echter, veelal zijn de handelingen en normen van de lidstaten het gevolg van hun EU-verplichtingen. Om die reden voorziet het Ontwerpakkoord in de mogelijkheid voor de EU of de lidstaten om betrokken te worden in procedures waarin de klacht tegen slechts een van beide werd ingediend, het zogenoemde medeverweerder-mechanisme ('co-respondent procedure'). ${ }^{14}$ Die procedure maakt het mogelijk dat de EU of een lidstaat vrijwillig tussenkomt als verwerende partij in procedures gericht tegen een van beide.

De EU wordt echter niet volledig gelijkgesteld met de andere lidstaten in het Ontwerpakkoord. Het Hof van Justitie had immers reeds in Advies 2/94 geoordeeld dat een toetreding van de EU tot het EVRM slechts verenigbaar was met het Unierecht indien dit de autonomie van het Unierecht niet in gevaar bracht. ${ }^{15}$ In dit advies moest het Hof van Justitie deze eis echter niet verder ontwikkelen aangezien het Hof van Justitie oordeelde dat de toetreding in elk geval onmogelijk was aangezien er geen rechtsbasis voor een toetreding voorzien was in de Verdragen. In Advies 1/00 verduidelijkte het Hof van Justitie dat het behoud van de autonomie in de eerste plaats vereist dat het essentiële karakter van de bevoegdheden van de EU en de EU-instellingen zoals voorzien in de Verdragen ongewijzigd blijft. ${ }^{16}$ In de tweede plaats mag toetreding tot een internationale

11. Voor een zeer uitgebreide en gedetailleerde beschrijving van het Ontwerpakkoord en de context van de toetreding zie P. Gragl, The Accession of the European Union to the European Convention on Human Rights, Oxford: Hart Publishing 2013, p. 362 en V. Kosta, N. Skoutaris en V. Tzevelekos, The EU Accession to the ECHR, Oxford: Hart Publishing 2014, p. 402.

12. Werkgroep CDDH-UE, Draft revised Explanatory report to the draft Agreement on the Accession of the European Union to the European Convention on Human Rights (hierna: Verklaring Toetredingsakkoord), 15 juni 2011, CDDH-UE(2011)11, par. 26.

13. Art. 46 EVRM.

14. Art. 3 Ontwerpakkoord. Voor een goede analyse van de procedure zie T. Lock, 'Walking on a Tightrope: the draft ECHR Accession Agreement and the Autonomy of the EU Legal Order', Common Market Law Review 2011, vol. 48, p. 1025.

15. HvJ 28 maart 1996, Advies 2/94 Advies over de toetreding van de Gemeenschap tot het Verdrag tot bescherming van de rechten van de mens en de fundamentele vrijheden, ECLI:EU:C:1996:140, Jur. 1996, p. I-1759.

16. HvJ 18 april 2002, Advies 1/00 krachtens artikel 300, lid 6 EG, ECLI:EU:C:2002:231, Jur. 2002, p. 1-3493. Reeds in het Advies 1/91 (EER) oordeelde het Hof van Justitie dat de autonomie van het Unierecht geschonden wordt indien een ander internationale rechtscollege niet alleen de rechtsnormen van het internationale verdrag mag uitleggen maar ook deze van de overeenkomstige Verdragen, zie HvJ 14 december 1991, Advies 1/91 aangaande het Verdrag Ontwerpakkoord tussen de Gemeenschap en de landen van de Europese vrijhandelsassociatie tot instelling van de Europese Economische Ruimte, ECLI:EU:C:1991:490, Jur. 1991, p. I-6079, punt 3. 
overeenkomst niet tot gevolg hebben dat de procedures voor het verzekeren van een uniforme interpretatie van het internationale verdrag, de EU en haar instellingen bindt aan een bepaalde interpretatie van het Unierecht voor de uitoefening van interne bevoegdheden. ${ }^{17}$

De eis van het behoud van de autonomie van de EU werd eveneens opgenomen in artikel 6 lid $2 \mathrm{VEU}$ en Protocol nr. $8 \mathrm{VEU}$ aangaande de toetreding van de EU tot het EVRM. Artikel 6 lid 2 VEU bepaalt dat de toetreding de bevoegdheden van de EU onverlet laat. Protocol nr. $8 \mathrm{VEU}$ werkt de eis van het behoud van de autonomie van de EU uit. Dit protocol vereist dat mechanismen worden voorzien om de 'specifieke kenmerken' van de EU te garanderen (art. 1 Protocol nr. 8 VEU) en om de bevoegdheden van de EU 'onverlet' te laten (art. 2 en 3 Protocol nr. 8 VEU). Dit betekent met name in de eerste plaats dat de toetreding geen uitbreiding van de bevoegdheden van de EU tot gevolg heeft. In de tweede plaats moet de centrale rol van het Hof van Justitie gegarandeerd worden voor wat betreft de interpretatie en toepassing van het Unierecht. ${ }^{18}$

Het Ontwerpakkoord houdt rekening met dit vereiste van behoud van autonomie. In de eerste plaats zijn er bepalingen opgenomen in het Ontwerpakkoord die de bevoegdheden van de EU moeten garanderen. Artikel 1 lid 3 van het Ontwerpakkoord bepaalt dat de toetreding de EU niet kan dwingen een handeling te stellen of rechtsnorm aan te nemen waarvoor zij niet bevoegd is. ${ }^{19}$ In de tweede plaats voorziet het Ontwerpakkoord in een mechanisme dat de exclusieve bevoegdheid van het Hof van Justitie verzekert om het Unierecht te interpreteren. In principe is een klacht tegen een lidstaat over een EVRM-schending slechts ontvankelijk indien de klager alle effectieve en voor handen zijnde nationale rechtsmiddelen uitputte. ${ }^{20}$ Als de EU tot het EVRM toetreedt, zal de klager alle voorhanden zijnde EU-procedures moeten uitputten. Echter, het Ontwerpakkoord bepaalt dat het EHRM niet zal onderzoeken of er aan de ontvankelijkheidsvoorwaarden is voldaan, en dus de uitputting van de voorhanden zijnde procedures wanneer de EU of een lidstaat optreedt als medeverweerder op basis van het co-respondentiemechanisme. ${ }^{21}$ De kans bestaat dan ook dat de EU optreedt als medeverweerder zonder dat het Hof van Justitie zich reeds heeft kunnen uitspreken over de mogelijke schending van het EVRM door de EU-norm of handeling die aangeklaagd wordt.

17. HvJ 18 april 2002, Advies 1/00, punt 12-13. Zie ook HvJ 30 mei 2006, zaak C-459/03, Commissie/lerland, ECLI:EU:C:2006,345, Jur. 2006, p. I-4635 of HvJ 8 maart 2011, Advies 1/09 aangaande Ontwerpovereenkomst over de invoering van een gemeenschappelijk stelsel voor octrooigeschillenbeslechting, ECLI:EU:C:2011:123.

18. Art. 3 protocol nr. 8 VEU bepaalt dat het Ontwerpakkoord de bevoegdheden van het Hof van Justitie vervat in art. 344 VWEU 'geheel onverlet' laat. Art. 344 VWEU bepaalt: 'De lidstaten verbinden zich, een geschil betreffende de uitlegging of de toepassing van de Verdragen niet op andere wijze te doen beslechten dan in de Verdragen is voorgeschreven.'

19. Art. 1 lid 3 Toetredingsakkoord.

20. Dit vereiste is opgenomen in art. 35 EVRM.

21. Art. 3 par. $1 \mathrm{~b}$ Ontwerpakkoord voorziet dat de ontvankelijkheid van de klacht wordt onderzocht zonder rekening te houden met de tussenkomst van de co-respondent.
Dit zou de exclusieve bevoegdheid van het Hof van Justitie in gevaar kunnen brengen. Om die reden voorziet het Ontwerpakkoord in de zogenoemde voorafgaande beoordelingsprocedure ('prior involvement procedure') waarbij het EHRM het Hof van Justitie de mogelijkheid geeft om de EU-norm of maatregelen te toetsen aan de rechten vervat in het EVRM indien de EU medeverweerster is en de verenigbaarheid nog niet heeft kunnen beoordelen. $^{22}$

\section{Advies 2/13}

Anders dan in zijn Advies 2/94 oordeelt het Hof van Justitie in Advies 2/13 dat met de inwerkingtreding van het Verdrag van Lisabon wel een rechtsbasis bestaat voor de toetreding van de EU tot het EVRM (punt 153). Artikel 6 lid 2 VEU voorziet samen met artikel 59 EVRM in een solide juridische basis om de toetreding mogelijk te maken. Bovendien bepaalt het Hof van Justitie dat de autonomie van de Unie en het Unierecht in principe er niet aan in de weg staat dat de EU toetreedt tot een internationale overeenkomst die voorziet in de oprichting van of de onderwerping aan een internationaal gerecht voor wat de interpretatie van deze verdragen betreft (punt 182). Het Hof van Justitie aanvaardt dan ook dat de uitlegging van het EVRM door het EHRM - en dus impliciet ook de veroordeling van de EU op basis van deze interpretatie - verbindend is voor de EU en de interpretatie van het EVRM door het Hof van Justitie niet bindend is voor het EHRM (punt 185). ${ }^{23}$ Het Hof vervolgt echter dat deze toetreding slechts verenigbaar is met het Unierecht als deze de 'constitutionele structuur van de Unie' waarborgt. ${ }^{24}$ Het Hof van Justitie oordeelt dat het Ontwerpakkoord onverenigbaar is met deze grondwettelijke structuur van de EU op maar liefst elf punten, verdeeld over de volgende vijf aspecten van het Ontwerpakkoord: (a) de autonomie van de EU en het Unierecht; (b) de positie van het Hof van Justitie; (c) het co-respondentiemechanisme; (d) de procedure van voorafgaande beoordeling; en (e) de mogelijkheid voor het EHRM om de regels en maatregelen te toetsen die vallen binnen het gemeenschappelijk buitenlands en veiligheidsbeleid (hierna: GBVB).

(a) De autonomie van de EU en het Unierecht Reeds uit Advies 2/94 weten we dat het Hof van Justitie de waarborg van de autonomie van het Unierecht als een cruciale toetssteen ziet voor de toetreding. Het Hof van

22. Art. 3 par. 6 Ontwerpakkoord. De Verklaring bij het voorstel verwijst expliciet naar het behoud van autonomie van de EU-rechtsorde bij de bespreking van de procedure. Verklaring Toetredingsakkoord, par. 30.

23. Het Hof van Justitie voegt daar wel meteen aan toe dat hetzelfde niet kan gelden voor de uitlegging van het Unierecht (punt 186). Zie hierna.

24. In punt 165 gebruikt het Hof van Justitie deze terminologie als koepel voor de voorwaarden waarvan de Verdragen de toetreding afhankelijk stellen, in het bijzonder de autonomie van het Unierecht. Deze voorwaarden bestaan uit de bevoegdheden toegekend aan de EU zoals opgenomen in art. 4 lid 1 en art. 5 lid 1 en 2 VEU alsook het institutionele kader van de EU zoals opgenomen in de art. 13-19 VEU. 
Justitie ziet op dit vlak drie grote lacunes in het Ontwerpakkoord.

Ten eerste wijst het Hof van Justitie erop dat het Ontwerpakkoord geen afstemming voorziet tussen artikel 53 EVRM en artikel 53 Handvest. Artikel 53 EVRM is de zogenoemde maximalisatieclausule. Deze bepaling verzet zich tegen een interpretatie van het EVRM die de bestaande bescherming van grondrechten in de lidstaten verlaagt. Artikel 53 Handvest voorziet een gelijkaardige maximalisatieclausule. Het Hof van Justitie oordeelde reeds dat dit artikel geen afbreuk doet aan het beschermingsniveau van het Handvest en aan de voorrang, de eenheid en de nuttige werking van het Unierecht (punt 188). ${ }^{25} \mathrm{Om}$ die reden meent het Hof van Justitie dat het Ontwerpakkoord slechts verenigbaar is met de autonomie van het Unierecht indien het Ontwerpakkoord de werking van artikel 53 EVRM beperkt voor zover noodzakelijk om geen afbreuk te doen aan het Handvest of de voorrang, eenheid en de nuttige werking van de EU (punt 189). Concreet lijkt het Hof van Justitie hiermee te willen vermijden dat lidstaten zich kunnen beroepen op artikel 53 EVRM om de voorrang of de nuttige werking van het Unierecht - de essentiële bouwstenen van de effectieve werking van het Unierecht volgens het Hof van Justitie - ter discussie te stellen.

Ten tweede oordeelt het Hof van Justitie dat er een lacune in het Ontwerpakkoord is nu er geen uitzondering voorzien werd op de mogelijkheid voor lidstaten om een klacht in te dienen tegen een andere lidstaat. Het EVRM bepaalt dat een lidstaat controleert of een andere lidstaat het Verdrag eerbiedigt terwijl het Unierecht voorschrijft dat de interactie tussen de lidstaten gebaseerd is op wederzijds vertrouwen. Indien EU-lidstaten klachten tegen elkaar kunnen indienen voor een schending van het EVRM in de toepassing van het Unierecht kan de toetreding het evenwicht waarop de Unie berust en de autonomie van het Unierecht in gevaar brengen. Het Hof van Justitie stuurt dan ook aan op een bepaling die EU-lidstaten verplicht hun twisten over de nietnaleving van het EVRM in de toepassing van het Unierecht op te lossen binnen het kader van het Unierecht.

In de derde plaats merkt het Hof van Justitie op dat het Ontwerpakkoord geen afstemming voorziet tussen de nieuwe prejudiciële adviesprocedure bij het EHRM en de prejudiciële procedure voor het Hof van Justitie zoals vervat in artikel $267 \mathrm{VWEU}$ (punt 196). Het nieuwe protocol nr. 16 EVRM voorziet dat lidstaten een nietbindend advies kunnen inwinnen bij het EHRM over de interpretatie van het EVRM. ${ }^{26}$ Op dit punt lijkt het Hof van Justitie de prioriteit van zijn eigen prejudiciële procedure te willen verzekeren. Het Hof van Justitie gaf in de context van een samenloop van de prejudiciële procedure voorzien in artikel 267 VWEU en nationale prejudiciële procedures reeds aan dat de nationale procedu-

25. HvJ 26 februari 2013, zaak C-399/11, Stefano Melloni /Ministerio Fiscal, ECLI:EU:C:2013:107, par. 60

26. Protocol nr. 16 EVRM werd pas goedgekeurd na het finale akkoord over het Ontwerpakkoord, maar het Hof van Justitie oordeelt dat protocol 16 EVRM integraal deel zal uitmaken van het EVRM en dat het Hof van Justitie hiermee dus rekening moet houden (punt 197). rele regels op geen enkele wijze de mogelijkheid van de nationale rechter mogen beknotten om een prejudiciële vraagstelling te stellen aan het Hof van Justitie. ${ }^{27}$

(b) De positie van het Hof van Justitie als hoogste rechter van het Unierecht

Het Hof van Justitie oordeelt dat het Ontwerpakkoord slechts verenigbaar is met het Unierecht als het de EU-lidstaten uitsluit van de interstatelijke klachtenprocedure voor het EHRM voor de uitvoering van het Unierecht in strijd met het EVRM. Deze procedure voorzien in artikel 33 EVRM maakt het mogelijk voor een lidstaat om een klacht in te dienen tegen een andere lidstaat van de Raad van Europa wanneer hij meent dat deze lidstaat het EVRM schendt.

Het Hof van Justitie oordeelt voorts dat de interstatelijke geschillenprocedure van het EVRM afbreuk doet aan het geschillenbeslechtingsmechanisme voorzien in artikel 344 VWEU omdat lidstaten ervoor kunnen kiezen om onderlinge geschillen over de toepassing van het EVRM aanhangig te maken bij het EHRM en niet bij het Hof van Justitie (punt 208). Artikel 344 VWEU bedeelt het Hof van Justitie de uitsluitende bevoegdheid toe in de beslechting van geschillen tussen de lidstaten: indien een lidstaat meent dat een andere lidstaat het Unierecht schendt, met inbegrip van de EU fundamentele rechten, moet hij deze klacht voorleggen aan het Hof van Justitie. ${ }^{28}$

(c) Het co-respondentiemechanisme

Het Hof van Justitie oordeelt dat dit mechanisme waarbij lidstaten of de EU als medeverweerder kunnen optreden onvoldoende garanties biedt voor het behoud van die eigenheid en autonomie. Ten eerste meent het Hof van Justitie dat het co-respondentiemechanisme aan het EHRM een rol toekent in de bevoegdheidsverdeling tussen de EU en de lidstaten doordat het EHRM mag oordelen of een lidstaat of de EU aan de voorwaarden voldoet om als medeverweerder op te treden. ${ }^{29}$ Een lidstaat kan slechts medeverweerder worden indien de klacht tegen de EU de verenigbaarheid van het EVRM met het primaire recht van de Unie ter discussie stelt. ${ }^{30}$ De EU kan op haar beurt medeverweerder worden als de klacht tegen de lidstaat de verenigbaarheid met het

27. Het Hof van Justitie somde een reeks voorwaarden in dit arrest op waaraan procedurele regels moeten voldoen die chronologische voorrang verlenen aan de nationale prejudiciële procedures: HvJ 22 juni 2010, zaak C-189/10, Melki en Abdeli, ECLI:EU:C:2010:206, Jur. 2010, p. I-5667. Meer hierover in J. Velaers, 'Het arrest-Melki-Abdeli van het Hof van Justitie van de Europese Unie: een voorwaardelijk "fiat" voor de voorrang van de toetsing aan de Grondwet op de toetsing aan het internationaal en het Europees recht', Rechtskundig Weekblad 2010-11, afl. 19, p. 770-794.

28. Het Hof van Justitie bepaalt over de interstatelijke procedure voor het EHRM in niet mis te verstane bewoordingen: 'Het loutere bestaan van deze mogelijkheid doet afbreuk aan het vereiste van art. 344 VWEU' (punt 208) en 'zou enkel een uitdrukkelijk uitsluiting van art. 33 EVRM (...) verenigbaar zijn met art. 344 VWEU' (punt 213).

29. Art. 3 par. 5 van het Ontwerpakkoord voorziet dat een lidstaat een verweerder kan worden op uitnodiging van het EHRM of op verzoek van de lidstaat zelf. Een lidstaat kan slechts medeverweerder worden als hij voldoet aan de voorwaarden gesteld in art. 3 par. 2-3.

30. Art. 3 par. 3 Ontwerpakkoord. 
Unierecht betreft. ${ }^{31}$ Het Hof van Justitie overweegt dat deze voorwaarden in wezen de bevoegdheidsverdeling tussen de EU en de lidstaten uitmaken waarvan de controle enkel het Hof van Justitie toekomt (punt 224-225). Bovendien verzet het Hof van Justitie zich tegen de mogelijkheid voor het EHRM om te oordelen of de lidstaat en de EU samen verantwoordelijk zijn of dat slechts een van beide verantwoordelijk is voor de EVRM-schending. Wederom meent het Hof van Justitie dat een dergelijke beslissing slechts mogelijk is na een analyse van de bevoegdheidsverdeling en de respectievelijke verantwoordelijkheden van de Unie en de lidstaten onder het Unierecht (punt 234). Deze taak komt enkel het Hof van Justitie toe.

Ten tweede oordeelt het Hof van Justitie dat het corespondentiemechanisme kan leiden tot een uitbreiding van de verplichtingen van een lidstaat onder het EVRM. Op basis van artikel 57 EVRM kunnen lidstaten voorbehouden formuleren ten aanzien van EVRM-bepalingen. Indien het EHRM de EU en de lidstaat gezamenlijk aansprakelijk zou houden na toepassing van het co-respondentiemechanisme, betekent dit dat het voorbehoud van deze lidstaat zonder voorwerp wordt. De toetreding van de EU tot het EVRM heeft voor deze lidstaat een uitbreiding van zijn verplichtingen onder het EVRM tot gevolg. Dit is volgens het Hof van Justitie in strijd met protocol nr. 8 VEU dat bepaalt dat de toetreding de situatie van de lidstaten ten aanzien van het EVRM onverlet laat.

(d) De voorafgaande beoordelingsprocedure

Het Hof van Justitie meent dat de uitwerking van de voorafgaande beoordelingsprocedure in het Ontwerpakkoord onvoldoende rekening houdt met de autonomie en eigenheid van het Unierecht en de rol van het Hof van Justitie. Ten eerste merkt het Hof van Justitie op dat het Ontwerpakkoord niet bepaalt wie mag bepalen of het Hof van Justitie zich reeds heeft uitgesproken over de rechtsvraag aan de orde in een procedure voor het EHRM. Deze beoordeling is volgens het Hof van Justitie opnieuw een vraag over de bevoegdheidsverdeling tussen de Unie en de lidstaten en komt dus enkel het Hof van Justitie toe (punt 236-237). Ten tweede verzet het Hof van Justitie zich ertegen dat de voorafgaande beoordelingsprocedure het Hof van Justitie enkel toelaat om uitspraak te doen over de verenigbaarheid van een bepaling van secundair recht met het primair Unierecht of over de uitlegging van het primaire recht. Het Hof van Justitie meent dat deze procedure ook moet toelaten dat het Hof van Justitie een bindende interpretatie voorziet van het secundair Unierecht (punt 234). Het Hof van Justitie meent dat dit ertoe kan leiden dat het EHRM het secundair Unierecht interpreteert wanneer er verschillende interpretaties mogelijk zijn, wat in strijd zou zijn met het monopolie van het Hof van Justitie om het Unierecht te interpreteren (punt 245-247). (e) Het gemeenschappelijk buitenlands en veiligheidsbeleid (GBVB)

Tot slot merkt het Hof van Justitie op dat het VEU nog steeds geen rechterlijke toetsing toelaat van de maatregelen genomen door de EU-instelling in het kader van het GBVB (punt 252). Dit betekent onder andere dat de handelingen van verschillende agentschappen van de Unie, zoals de Frontex-operaties in het kader van het gemeenschappelijk asiel- en migratiebeleid, aan de controle van het Hof van Justitie ontsnappen. De toetreding maakt het EVRM echter wel bevoegd om hierover te oordelen. Het Hof van Justitie oordeelt dat de bevoegdheid om een rechterlijke controle uit te oefenen op maatregelen van de Unie niet exclusief overgedragen kan worden aan een internationaal gerecht (punt 256). Dit betekent dat zolang het Hof van Justitie geen controle krijgt over het GBVB, ook het EHRM verstoken zal blijven van deze toetsing.

\section{Advies 2/2013: een tussenstop of het einde van de rit?}

Advies 2/2013 maakt duidelijk dat het Ontwerpakkoord zoals het nu voorligt onverenigbaar is met het Unierecht. De toetreding op basis van dit Ontwerpakkoord is dan ook onmogelijk. ${ }^{32}$ Indien men al de politieke steun zou kunnen vinden voor heronderhandelingen van het Ontwerpakkoord, ${ }^{33}$ is het de vraag of deze punten uiteindelijk opgenomen kunnen worden.

Bepaalde punten van het Advies zijn in principe eenvoudig te verhelpen, omdat zij slechts een kleine aanpassing vereisen, niet raken aan de uitgangspunten van dit Ontwerpakkoord en geen gevolgen hebben voor de niet EU-lidstaten. Dit is bijvoorbeeld het geval bij de mogelijkheid voor EU-lidstaten om gebruik te maken van de interstatelijke klachtenprocedure voor het EHRM wanneer zij menen dat een andere EU-lidstaat het EVRM schendt in de toepassing van het Unierecht (punt (b) van deze bijdrage). Het is niet onoverkomelijk om de ontvankelijkheid van een dergelijke interstatelijke klacht afhankelijk te stellen van de uitputting van de geschillenprocedure voor het Hof van Justitie of zelfs deze mogelijkheid uit te sluiten. De EU-lidstaten hebben reeds anvaard hun geschillen over dergelijke punten

32. Een advies van het Hof van Justitie is immers bindend. Art. 218 lid 11 VWEU.

33. Het Ontwerpakkoord is op dit moment reeds de uitkomst van een compromis tussen de EU en niet-EU-lidstaten, de EU en de Raad van Europa. De onderhandelingsmarge lijkt dan ook beduidend klein. Zo gaf Rusland aan dat sommige van de gesloten compromissen voor Rusland zeer moeilijk lagen, maar dat het daar uiteindelijk toch in toestemde. Indien de onderhandelingen heropend moeten worden vanwege 'interne problemen van de EU' sluit Rusland dan ook niet uit dat het zelf amendementen zal voorstellen op het Ontwerpakkoord. Appendix VI (Statement made by the Representative of the Russian Federation), Tweede vergadering tussen de $\mathrm{CDDH}$ ad hoc onderhandelingsgroep en de Europese Commissie aangaande de toetreding van de Europese Unie tot het Europees Verdrag voor de Rechten van de Mens, rapport van de 75ste vergadering van de CDDH (Straatsburg 17-19 september 2012). 
voor te leggen aan het Hof van Justitie toen zij lid werden van de EU en kunnen hiertegen dan ook geen bezwaar hebben. Voor de niet-EU-lidstaten wijzigt hierdoor niets aan hun eigen positie of hun positie ten aanzien van de ander verdragsluitende partijen van het EVRM.

Ook lijkt er geen fundamenteel bezwaar te bestaan tegen een aanvulling van het Ontwerpakkoord om vragen over de verenigbaarheid van het EVRM met nationale bepalingen die binnen het toepassingsgebied van de Unie vallen uit te sluiten van de adviesprocedure zoals uitgewerkt in protocol nr. 16 EVRM of de prioriteit van de prejudiciële procedure voor het Hof van Justitie te erkennen (punt (a) van deze bijdrage). Lock merkte echter terecht in zijn commentaar bij het Advies op dat deze eis van het Hof van Justitie voor kritiek vatbaar is omdat een dergelijk advies onder protocol nr.16 EVRM niet-bindend is in tegenstelling tot de prejudiciële procedure voor het Hof van Justitie voorzien in artikel 267 VWEU. ${ }^{34}$ Bovendien wordt nergens in het Ontwerpakkoord noch in protocol nr.16 EVRM gesuggereerd dat deze procedure voorrang zou hebben op andere nationale of internationale procedures. Het is onduidelijk hoe deze vrijwillige adviesprocedure dan ook in concurrentie kan komen met de prejudiciële procedure voor het Hof van Justitie. ${ }^{35}$

Andere punten van het Advies zijn echter van meer fundamentele aard. Het Ontwerpakkoord is op deze punten minder eenvoudig aan te passen omdat zij een uitzonderingspositie van de $\mathrm{EU}$, in het bijzonder van het Hof van Justitie, ten aanzien van de andere lidstaten versterken. Deze kritiek van het Hof van Justitie stelt dan ook de gelijkschakeling tussen de EU als verdragsluitende partij en andere lidstaten ter discussie en daardoor ook het bereikte evenwicht in het akkoord. Immers, het corespondentiemechanisme en de voorafgaande beoordelingsprocedure moesten reeds de eigenheid van de Unie en positie ven het Hof van Justitie vrijwaren. De vraag is dan ook hoeveel verder de andere lidstaten willen gaan in het toekennen van een verdergaande uitzonderingspositie voor het Hof van Justitie.

Zo verzet het Hof van Justitie zich tegen elke beoordeling door het EHRM die mogelijk, rechtstreeks of onrechtstreeks, kan raken aan zijn prerogatieven onder het Unierecht (punt (c) en (d) van deze bijdrage). Op sommige punten is het Hof van Justitie te volgen. Zo meent het Hof van Justitie dat het EHRM in een co-res-

34. T. Lock, 'Oops! - We did it again - the CJEU's Opinion on EU Accession to the ECHR', <www.verfassungsblog> (18 januari 2014).

35. De prejudiciële procedure voor het Hof van Justitie is echter niet vrijblijvend voor de nationale rechtscolleges. Art. 267 VWEU bepaalt dat nationale rechtscolleges het Hof van Justitie een prejudiciële vraag moeten stellen indien er vragen zijn over de interpretatie van de Verdragen, en dus de EU-fundamentele rechten, of de geldigheid en interpretatie van het secundair Unierecht, en dus de verenigbaarheid van het secundair Unierecht met fundamentele rechten. Het Hof van Justitie voorzag bovendien in een uitgebreide rechtspraak met richtlijnen voor nationale rechtscolleges om te verwijzen. Zie hierover P. Craig, 'The classics of EU law revisited: CILFIT and Foto-Frost', in: M. Maduro en L. Azoulai (red.) The Past and Future of EU Law: The Classics of EU Law Revisited on the 50th Anniversary of the Rome Treaty, Londen: Hart Publishing 2010, p. 185-191. pondentiemechanisme zich niet mag uitspreken over wie verantwoordelijk is voor de schending. Terecht merkt het Hof van Justitie op dat dit een oordeel over de bevoegdheidsverdeling zou inhouden. Op dit punt zou het Ontwerpakkoord kunnen voorzien dat zodra de lidstaat en de EU als medeverweerders optreden, zij samen aansprakelijk gesteld zullen worden indien er een schending van het EVRM is. Het is dan aan de EU om interne procedures te voorzien om binnen het Unierecht de gepaste maatregelen te treffen en verantwoordelijkheden aan te duiden. Op dit vlak moet de situatie van de EU niet danig verschillen van een federale staat waarbij eveneens nationale afspraken bestaan over het remedieren van EVRM-inbreuken die exclusief of overlappend zijn tussen de federale staat en de regionale entiteiten.

Dit geldt echter niet voor het verzet van het Hof van Justitie tegen de bevoegdheid voor het EHRM te oordelen over een verzoek van een lidstaat of de EU om op te treden als medeverweerder. Het Hof van Justitie oordeelt dat een dergelijke beslissing noodzakelijkerwijze ook een oordeel over de bevoegdheidsverdeling tussen de EU en de lidstaten inhoudt. Het Hof van Justitie vergeet daarbij te vermelden dat de toetsing door het EHRM slechts marginaal is en geen eindoordeel over de bevoegdheidsverdeling tussen de lidstaten en de EU. Immers, het Ontwerpakkoord schrijft voor dat het EHRM een lidstaat kan toelaten als medeverweerder op te treden als een klacht mogelijk ('if it appears') de verenigbaarheid van het EVRM met het primair recht ter discussie stelt. Dit is eveneens het geval voor de situatie waarin de EU verzoekt als medeverweerder op te treden: in dat geval zal het EHRM de EU toelaten tot de procedure als het erop lijkt dat de klacht eveneens de verenigbaarheid van het EVRM met het secundair Unierecht aan de orde stelt. Bovendien moeten we vaststellen dat het EHRM momenteel reeds dergelijke oordelen velt. Wanneer het EHRM geconfronteerd wordt met een klacht tegen een lidstaat voor een maatregel of een rechtsregel die volgt uit het Unierecht, makt het EHRM een inschatting op basis van de Bosphorus-doctrine of deze handeling of regel binnen de discretionaire ruimte van de lidstaat valt of rechtstreeks volgt uit zijn EU-verplichtingen. ${ }^{36}$ Nochtans wordt deze rechtspraak aanvaard als de basis voor de huidige harmonieuze modus vivendi tussen het EHRM en het Hof van Justitie. ${ }^{37}$ In dezelfde lijn ligt het oordeel van het Hof van Justitie met betrekking tot de voorafgaande beoordelingsprocedure. Het Hof van Justitie is van oordeel dat het in deze procedure enkel kan toetsen of het secundaire Unierecht verenigbaar is met de EU-fundamentele rechten, maar geen bindende interpretatie van het secundair Unierecht kan geven. In de eerste plaats moet hierbij opgemerkt worden dat er evenmin een garantie bestaat voor de nationale hoogste rechtscolleges dat hun interpretatie

36. EHRM 30 juni 2005, nr. 45036/98, Bosphorus/lerland, EHRC 2005/91, m.nt. Bulterman. Zie hierover J. Callewaert, 'Het EVRM en de Europese Unie: van Bosphorus naar Lissabon', NTER 2010/3, p. 101-107.

37. Zie hierover uitgebreid C.J. Van de Heyning, 'De Toetreding van de EU tot het EVRM: goede afspraken maken goede vrienden', TVCR 2012, p. $230-248$. 
van het nationale recht gevolgd zou worden door het EHRM. In de tweede plaats is de bezorgdheid van het Hof van Justitie op dit vlak onterecht. Het is immers vaststaande rechtspraak van het EHRM dat het hem niet toekomt om zijn eigen visie in de plaats te stellen van de eigen interpretatie en inhoud van het nationaal recht. ${ }^{38} \mathrm{Er}$ is dan ook geen reden om aan te nemen waarom het EHRM dit zou doen bij het Hof van Justitie. In zijn toetsing van de verenigbaarheid van het secundair recht met de EU-fundamentele rechten zal het Hof van Justitie immers een bepaalde interpretatie naar voren schuiven. Ook al is deze interpretatie formeel niet bindend, het Hof van Justitie had kunnen besluiten dat op basis van de EHRM-rechtspraak deze interpretatie wel degelijk gevolgd zou worden door het EHRM. Zonder twijfel zal het Hof van Justitie de meeste kritiek oogsten met zijn verzoek om de maatregelen in het kader van het GBVB uit te sluiten van de EHRM-controle. In wezen neemt het Hof van Justitie het standpunt is dat zolang het deze maatregelen niet kan toetsen, het EHRM deze controle ook niet mag uitoefenen. Peers noemt deze redenering terecht verbijsterend ('mindboggling'): 'In short, since it isn't allowed to play, it's taking the football away from everyone else. It's the judicial politics of the playground. ${ }^{39}$

De uitbreiding van de bevoegdheid van het Hof van Justitie tot het GBVB kan bovendien alleen volgen uit een aanpassing van het Verdrag van de Europese Unie en kan niet geremedieerd worden door het Ontwerpakkoord. Het uitsluiten van de bevoegdheid van het EHRM om maatregelen binnen het GBVB te controleren kan er dan weer toe leiden dat andere lidstaten van het EVRM eveneens een dergelijke uitzondering wensen. Daarenboven is het feit dat er vandaag geen enkele juridische controle is over de verenigbaarheid van het GBVB met mensenrechten één van de belangrijkste redenen waarom voorstanders de toetreding tot het EVRM bepleiten.

\section{Conclusie}

In de eerste reacties wordt dit advies als een zware slag voor de toetreding beschouwd. Het Britse The Lam Gazette kopte 'EU court snubs human rights accession'. ${ }^{40}$ Van der Mei schreef: 'Court of Justice bars EU accession to the ECHR!' ${ }^{11}$ Douglas-Scott noemde

38. Het EHRM oordeelde in Z/Verenigd Koninkrijk onomwonden dat het niet zijn taak is 'substituting its own views as to the proper interpretation and content of domestic law'. Vrije vertaling: 'zijn eigen visie op de juiste interpretatie en inhoud van het nationaal recht in de plaats te stellen'. EHRM 10 mei 2001, appl. nr. 29392/95, Z/Verenigd Koninkrijk, punt 101.

39. S. Peers, 'The CJEU and the EU's accession to the ECHR: a clear and present danger to human rights protection', <www.eulawanalysis. blogspot.be> (18 december 2014).

40. M. Cross, 'EU court snubs human rights accession', <www.lawgazette. co.uk> (18 december 2014)

41. A.P. van der Mei, 'Court of Justice bars EU accession to the ECHR!', <www.law.maastrichtuniversity.nl> (18 december 2014). het Advies een 'Christmas bombshell'42 en Peers koos voor het dramatische 'an unmitigated disaster'. ${ }^{43}$ Wat er ook van zij, in elk geval is de toetreding niet voor morgen. Het Hof van Justitie vraagt op cruciale punten dat het Ontwerpakkoord aangepast wordt. Het is maar zeer de vraag of er een nieuw compromis gevonden kan worden gezien het feit dat het Ontwerpakkoord reeds de uitkomst was van moeizame onderhandelingen.

42. S. Douglass-Scott, 'Opinion $2 / 13$ on EU Accession to the ECHR: a Christmas bombshell from the European Court of Justice', <www. ukconstititonallaw.org> (24 januari 2014).

43. S. Peers, 'The CJEU and the EU's accession to the ECHR: a clear and present danger to human rights protection', <www.eulawanalysis. blogspot.be> (18 december 2014). 